\title{
Outcomes of a comprehensive, large-scale child growth and health promotion program implemented at a national level and in the long term
}

\section{INTRODUCTION}

From a public health perspective, there are three major nutrition indicators: height for weight, weight for age, and height for age. The latter is not only an expression of undernutrition but the result of pre- or postnatal growth retardation, which is influenced by a series of health-related factors: frequent infections and hospitalizations, nutritional deficiencies, contaminants, poor sanitation conditions, etc. Stunting and the overall health status of children share the main social determinants of health and, therefore, stunting serves as a primary indicator to be considered in every public health action. Stunting does not resolve by providing an adequate diet; on the contrary, it requires a very wide range of health actions.

For this reason, the article commented here ${ }^{1}$ deserves a special mention in the history of growth and nutrition in Argentina because it describes the outcomes of a comprehensive, staterun, child health program with a very extensive coverage, sustained in the long term and with a highly favorable impact.

\section{Comment}

That article is the result of the work of a group of investigators, including Pablo Núñez and Daniel Salomón from the National Institute of Tropical Medicine of Misiones and the National Scientific and Technical Research Council (Consejo Nacional de Investigaciones Científicas y Técnicas, CONICET). It also included Fernández-Slezak from the Artificial Intelligence Lab of Universidad de Buenos Aires (UBA), Andrés Farall, from Ecoclimasol of Buenos Aires, María Eugenia Szretter from the Calculus Institute of Universidad de Buenos Aires, Claudia R. Valeggia from the Yale University's Department of Anthropology (New Haven, CT).

The objective of that study was to estimate the trends of undernutrition (stunting and underweight) among children younger than 5 years covered by the programs Plan Nacer and Programa Sumar in the 2005-2013 period. These programs collected high-quality, reliable information on birth and visit dates, age (in days), gender, weight (in $\mathrm{kg}$ ), and height (in $\mathrm{cm}$ ) for 1.4 million children younger than 5 years in 6386 health centers (13 million records), which accounted for a broad coverage of the vulnerable child population in Argentina.

Argentina's government implemented Plan Nacer in 2004, which introduced changes aimed at reinforcing a national health system that depicted important jurisdictional asymmetries following the economic crisis in 2001. Its main components were an increased coverage and access to health care and a greater equity in access and quality of health services, prioritizing pregnant women and children younger than 5 years.

Programa SUMAR was launched in 2013 and extended health care services to 5.7 million children and adolescents (0-19 years) and 3.8 million women younger than 64 years.

Both programs were implemented synergistically with the cash transfer programs Asignación Universal por Hijo and Asignación Universal por Embarazo to provide health prevention, education, and nutrition services. Health centers provided the information to the Ministry of Health, where it was centralized. Information was validated and processed using linear mixed effect regression models to estimate the trends of underweight and severe underweight, stunting and severe stunting in the 2005-2012 period of Plan Nacer. According to the data, they fell below a standard deviation (SD) of -2 or -3 based on the World Health Organization (WHO) tables, respectively. The database was processed using a strict statistical method, adjusting results to two main sources: inequality bias in the number of children by age (stunting and underweight varied with age) and health center enrollment at different times during the program.

\section{Stunting}

Based on the model, the prevalence of stunting among children younger than 5 years decreased from $20.6 \%$ in 2005 to $11.3 \%$ in 2013, which accounted for a $45 \%$ reduction. In rural areas, the reduction went from $23.0 \%$ to $13.7 \%$ whereas in urban areas, it reduced from $20.4 \%$ to $11.1 \%$. The prevalence of stunting was higher 
among boys than girls. Once the five Argentine regions were analyzed, significant decreasing trends were observed across all of them. Relative decrease rates by region ranged from $45 \%$ in Northwest Argentina to $15 \%$ in the Central Region. Severe stunting (-3 SD) decreased from $3 \%$ in 2005 to $1.5 \%$ in 2012.

\section{Underweight}

The prevalence of underweight decreased from $4.0 \%$ to $2.5 \%$, which accounted for a $38 \%$ reduction. Unlike what was observed for stunting, no differences were found between rural and urban areas, although boys always showed a higher prevalence of stunting than girls. Such reduction was observed across all regions and ranged from 75\% in Northwest Argentina to 25\% in the Central Region.

\section{Comment}

In Latin America, several programs were created to achieve significant improvements in the decline of undernutrition prevalence. In Brazil, stunting decreased from $37.0 \%$ to $7.0 \%$ between 1974 and 2007 following the universalization of health care coverage through the Bolsa Família program and other interventions. ${ }^{3}$ Similarly, the Oportunidades program reduced stunting in Mexico from 27\% to $16 \%$ between 1988 and $2006,{ }^{4}$ and included universal health access and cash transfers. There were other programs with varied results in different countries. ${ }^{5,6}$

Nevertheless, this study is exceptionally valuable because it provides information on the coverage of the studied population, conducted a strict assessment, and included relevant statistical techniques and an adequate study period.

Results obtained in relation to stunting reduction are evident, and also important, because it is known that stunting is a reliable indicator for child health inequalities. Once again, growth retardation preceding stunting is not the result of only one nutritional cause but of a multifactorial group of health problems, low birth weight, frequent infections (otitis, diarrhea, bronchiolitis), frequent hospitalizations, iron deficiency anemia, other nutritional deficiencies, etc.

The study is highly representative of the Argentine vulnerable population, with indicators that are descriptive of children's overall health. Their health is influenced by multiple social determinants, and probably because of this, the authors refer that "the reduction in the prevalence of stunting is probably owing to more than the implementation of Asignación Universal por Hijo and cash transfers."

The authors underlined that, in the past decade, the Argentine economy showed a period of sustained growth, accompanied by an increased spending in public health, which is consistent with a high reduction in poverty and indigence, an increase in the employment rate and in the access to clean water, hygiene, and sanitation, and a free public immunization program associated with a $27.0 \%$ reduction in the infant mortality rate (14.3-10.8 per 1000$)$ and a $17.0 \%$ reduction in the maternal mortality rate (3.9-3.2 per 10000 ) between 2005 and 2013.7

It is worth noting that, in all studied series, boys showed a greater proportion of stunting than girls, a universal finding that is related to the fact that boys are at a "greater risk" (girls are better genetically canalized) and that for a "deviation" to occur in a girl's growth percentile, a much worse lesion is required than that required to deviate a boy.

In my opinion, this article is a highly valuable document for the assessment and scientific analysis of a state-run crucial intervention and its impact on one of the most descriptive child health indicators: physical growth. ${ }^{8}$

\section{Prof. Horacio Lejarraga, M.D.} Universidad de Buenos Aires

http:/ / dx.doi.org/10.5546/ aap.2017.eng.524

To cite: Lejarraga H. Outcomes of a comprehensive, large-scale child growth and health promotion program implemented at a national level and in the long term. Arch Argent Pediatr 2017;115(6):524-526.

\section{REFERENCES}

1. Nuñez PA, Fernández-Slezak D, Farall A, et al. Impact of Universal Health Coverage on Child Growth and Nutrition in Argentina. Am J Public Health 2016;106(4):720-6.

2. De Brauw A, Gilligan D, Hoddinott J, et al. The Impact of Bolsa Família on Child, Maternal, and Household Welfare. Washington, DC: International Food Policy Research Institute; 2012.

3. Atun R, de Andrade LO, Almeida G, et al. Health-system reform and universal health coverage in Latin America. Lancet 2015;385(9974):1230-47.

4. Boerma T, Eozenou P, Evans D, et al. Monitoring progress towards universal health coverage at country and global levels. PLoS Med 2014;11(9):e1001731. 
5. De Andrade LO, Pellegrini Filho A, Solar O, et al. Social determinants of health, universal health coverage, and sustainable development: case studies from Latin American countries. Lancet 2015;385(9975):1345-51.

6. Manley J, Gitter S, Slavchevska V. How Effective Are Cash Transfer Programmes at Improving Nutritional Status? A Rapid Evidence Assessment of Programmes' Effects on Anthropometric Outcomes. London, UK: EPPI-Centre, Social Science Research Unit, Institute of Education, University of London; 2012.
7. Gertler P, Giovagnoli P, Martinez S. Rewarding Provider Performance to Enable a Healthy Start to Life: Evidence From Argentina's Plan Nacer. Washington, DC: World Bank; 2014.

8. Lejarraga $\mathrm{H}$. El crecimiento físico como indicador de salud y bienestar socioeconómico de la población. In INDEC. Infancia y condiciones de vida:encuestaespecial parael diagnóstico y la evaluación de las metas sociales. Buenos Aires: INDEC; 1995. Pages 101-26. 